\title{
Cross-Modal Morphological Priming in French
}

\author{
Fanny Meunier
}

Laboratoire Dynamique du Langage, CNRS and Université Louis Lumière Lyon 2, Lyon, France

and

Juan Segui

Laboratoire de Psychologie Expérimentale, CNRS and Université René Descartes Paris V, Boulogne Billancourt, France

Published online November 16, 2001

\begin{abstract}
We investigated the lexical representation of morphologically complex words in French using a cross-modal priming experiment. We asked if the lexical representation for derivationally suffixed and prefixed words is morphologically structured and how this relates to the phonological transparency of the surface relationship between stem and affix. Overall we observed a clear effect of the morphological structure for derived words, an effect that is not explicable by a formal effect. Prefixed words prime their stems, even when they have a phonologically opaque relationship, and a prefixed word primes another prefixed word derived from the same stem. However, suffixed words prime their stems only if their relationship is phonologically transparent. Two suffixed words derived from the same stem prime each other. These two latter results differ from those observed in English by Marslen-Wilson, Tyler, Waksler, and Older (1994). We argue that it is the specific properties of the language, such as rhythm, that could explain the differences between the results observed for the two languages and we propose a model where prefixed and suffixed words are decomposed at different stages during their identification process. ๑ 2001 Elsevier Science (USA)
\end{abstract}

Key Words: derived word; cross-modal priming; cross-language studies.

The purpose of this work is to provide information about the lexical representation of morphologically complex words in French. In the experiment that we present in this article, we asked if the lexical representations of derivationally suffixed and prefixed French words are morphologically structured and how this relates to the phonological transparency of the surface relationship between stem and affix.

The way morphologically complex words are stored and accessed has been widely studied and many models have been proposed (see McQueen \& Cutler, 1998, for a review). The models suggested make claims about the processing of complex words and the kind of representation that is accessed. To a large extent, such models are located between two extreme propositions: either a left-to-right processing associated with a global word representation (Butterworth, 1983; Manelis \& Tharp, 1977) or a prelexical decomposition associated with a morpheme-decomposed representation

This research was supported by the French Ministry "de l'enseignement supérieur et de la recherche.' We thank Matthew Brett for his help and suggestions.

Address correspondence and reprint requests to Fanny Meunier, Laboratoire Dynamique Du Langage, CNRS-UMR 5596, Institut des Sciences de l'Homme, 14 avenue Berthelot, 69363 Lyon Cedex 07, France. E-mail: Fanny.Meunier@ish-lyon.cnrs.fr. 
(Taft \& Forster, 1975). Many researchers have proposed some compromise between these extremes. Some have suggested decomposition processing and/or representation only for particular complex words such as frequent words (Bybee, 1985; Schreuder \& Baayen, 1995), semantically transparent words (Marslen-Wilson, Tyler, Waksler, \& Older, 1994; Schreuder \& Baayen, 1995), words with productive affixes, and suffixed words versus prefixed words (Stanners, Neiser, Hernon, \& Hall, 1979). Others have claimed two competing routes with a race between them (Caramazza, Miceli, Silveri, \& Laudanna, 1985; Frauenfelder \& Schreuder, 1992). Furthermore, language-specific cognitive models of morphologically complex words have been proposed for the different types of morphology occurring in different languages. Indeed, across languages, the structure and the prevalence of morphologically complex words vary. Complex words differ with respect to the phonological and orthographic variability of their morphemes, and this influences the salience of their segmentability into constituent morphemes (Comrie, 1981). Studies on Finnish, Serbo-Croatian, Turkish, Chinese, Hebrew, and Arabic showed the implications of these structural variations on the way that components of a word are processed. However, for languages that have a closely related morphological system, the specificity of language is rarely discussed. Studies on derived morphology in English, Italian, Dutch, Spanish, and French are usually interpreted in the framework of the same cognitive models. The experiment presented in this article was carried out partly to compare the role of morphology in two languages that have close morphological systems: French and English. Both languages have a concatenative morphology that is not extensively productive. They use the same kind of affixes: suffixes for inflection and prefixes and suffixes for derived morphology. However, results from one language cannot be directly interpreted as evidence about the organization of the lexicon in another language, not only because there may be different morphological systems but also because of the difference of the nature of lexical processes across languages (see, for example, studies on phonological and orthographic codes for lexical access, e.g. Frost, Katz, \& Bentin, 1987; Katz \& Feldman, 1983).

Across languages the topic of the lexical representation of morphologically complex words has generated many studies, most of them using the procedure of priming. In line with the morphological hypothesis these researches have shown, for example, that the prior presentation of a morphological complex words (ex, refaire) facilitates the subsequent processing of its root component (ex, faire) (for translation of French words used in the text, see Appendix A). This effect has been attributed to the implementation of a procedure of decomposition of the derived word into the morphemic constituents of affix and stem (Taft \& Forster, 1975). More generally, one observes an effect of facilitation when the word-prime and the word-test stem from the same morphological family (Burani \& Laudanna, 1992; Butterworth, 1983; Drews \& Zwitserlood, 1995; Feldman, 1994; Fowler, Napps, \& Feldman, 1985; Grainger, Colé, \& Segui, 1991; Kempley \& Morton, 1982; Marslen-Wilson et al., 1994). These results suggest that the presentation of a word belonging to a morphological family in the mental lexicon of the subject activates the other members of this family. Nevertheless, the size of the facilitation effect varies according to parameters that are not all clearly identified.

Our experiment used the cross-modal repetition priming paradigm that has been fruitfully used to study morphological effects (Feldman \& Larabee, 2001; MarslenWilson et al., 1994; Meunier \& Segui, 1999b). In this paradigm subjects hear a prime word and, at its acoustic offset, see a target item. They had to make a lexical decision to the word or nonword visually presented. We used this paradigm because we assume that it taps selectively into activation effects at the level of the lexical representation and is not sensitive to purely phonological or orthographic overlap between 
prime and target at lower levels of the system. Given that the lexical entry is modalityspecific, if a spoken word primes a visually presented word, this must be via some central lexical representation.

One of the most extensive papers on derivational morphology is that of MarslenWilson and collaborators (1994), which describes many experiments investigating the relationship of different members of morphological families in English. MarslenWilson et al. (1994), using a cross-modal paradigm, observed that suffixed forms (e.g., friendly) primed and were primed by their stems, but that suffixed forms did not prime each other (e.g., confession and confessor). Derivationally prefixed forms (e.g., unfasten and refasten) primed and were primed by their stems, but, in contrast to suffixed forms, they also primed each other. Prefixed and suffixed forms sharing the same stem primed each other as well (e.g., distrust and trustful). The striking lack of priming between two suffixed words has been replicated with other items by Feldman and Larabee (2001). Moreover, similar lack of priming between two suffixed words derived from the same stem was obtained using an auditory-auditory priming paradigm (Marslen-Wilson \& Zhou, 1999). Marslen-Wilson and his collaborators attribute this lack of effect (co-occurring with other morphological effects such as that observed between a suffixed word and its stem) to the existence of inhibitory relationships between suffixes that can be combined with a particular decomposed lexical representation. They proposed a model in which lexical representations are morphologically decomposed, with affixes clustered around shared stem morphemes. Priming takes place through repeated access to stems. All members of a cluster therefore activate each other. However, suffixed forms do not prime each other because additional inhibitory links between suffixes of a cluster cancel out any benefit due to repeated access of the stem. Marlsen-Wilson et al. justify these inhibitory connections on the grounds that when the listener encounters a suffixed form, the stem will be heard first, and this will activate both the stem itself and different suffixes that can be attached to it. As soon as the evidence is available to select one suffix over another, these suffixed competitors will be suppressed. This slows responses to one of these competitors if it is subsequently presented as a target in the priming paradigm. Pairs like attractive and attraction would be mutually exclusive: The same lexical representation (the stem morpheme attract) cannot simultaneously be interpreted as two different lexical items (attract + ive and attract + ion). No such connections are required between prefixes: a given prefix will not activate other prefixes of the same stem, so they need not be suppressed.

A competition effect between suffixed words derived from the same stem has also been shown in French (Meunier \& Segui, 1999a) using a simple lexical decision task with auditory word presentation. Suffixed words with more frequent suffixed candidates derived from the same stem are recognized slower than suffixed words with less high frequency competitors. The authors propose an explanation compatible with the one proposed by Marslen-Wilson et al. (1994): The stem which begins the suffixed word activates a cohort of candidates corresponding to the suffixed members of the morphological family. A matching process, then, selects the right candidate, the word corresponding to the target. The candidates in the "morphological cohort" (i.e., suffixed words sharing the same stem) are examined on the basis of their surface frequency; more frequent candidates are examined before less frequent ones. In common between the Marslen-Wilson account and Meunier and Segui account is the importance that different words share simultaneously an initial cohort (MarslenWilson \& Welsh, 1978) and a lexical representation. The experiment presented in the present article had the aim of testing if using exactly the same method and design as Marslen-Wilson et al. (1994) we would observe, in French, the same pattern of results as the one observed in English. In particular we wanted to look for an interac- 
tion between morphological priming and the type of target-suffixed word or stempresented after a suffixed prime.

Is the French lexical representation structured morphologically, irrespective of whether morphologically related words are phonologically transparent or opaque (allomorphs)? Is there a level of morphologically structured lexical representation that is at a more abstract level than the surface phonetic properties of word forms belonging to morphologically related families? More specifically we looked at (1) the role of phonological transparency between derived words and their stems by comparing the priming effects for pairs like brutal-brute and refaire-faire (phonologically transparent) and pairs with an allomorphic prime such as chaleur-chaud and imberbe-barbe (phonologically opaque); and (2) the role of the type of links between two words derived from the same stem. In this case we compared the priming effect between two suffixed words (such as jardinier-jardinage) and two prefixed words (such as refaire-défaire). This comparison allowed us to establish the role of the order of the component stem-affix on derived word processing. We also looked at (3) the role of morphological links compared to phonological links. By comparing pairs like amoral-moral (morphologically related) to pairs such as alarme-larme (formally related) and pairs like acidité-acide (morphologically related) to pairs such as charité-char (formally related), we wanted to establish whether the morphological priming effect differed from the formal priming effect. We also investigated (4) the role of morphological links compared to semantic links. By comparing pairs like amoral-moral (morphologically related) to pairs such as infirmière-docteur (semantically related), we investigated whether the morphological priming effect is reducible to the semantic priming effect. In our experiment, we defined morphological relatedness between words on linguistic, historical, and empirical grounds. Two words were considered as morphologically related if they met the three following criteria: (1) the derived form had recognizable stem and affix; (2) the two words of a pair shared the same historical source word (the etymon), as determined by the Dictionnaire historique de la langue française (Rey, 1995); and (3) participants labeled them as belonging to the same morphological family (established with a pretest). These checks permitted us to exclude the risk of pairs that had coincidentally homophonic stems. Pairs of words were defined as having a phonologically transparent relationship if the stem was the same phonologically and orthographically as a free form and within the derived word and if the stem was followed or preceded by a clearly identifiable separable affix, as the -al in verbal. In general, a pair was designated as not having a phonologically transparent relationship if there were any vowel or consonantal alternation between the stem and the derived word such as bestialbête.

As explained before, our experiment used the cross-modal repetition priming paradigm, where subjects hear a prime word and, at its acoustic offset, see a target word on which they had to make a lexical decision. The interesting contrast is between decision latencies to the visual target word when it occurs after a related prime word as opposed to an unrelated control prime. If the stem of a word is accessed when listeners hear a derived word (e.g., brutal), then when they see the stem (e.g., brute) after hearing the derived word, their latencies to make a lexical decision will be facilitated, relative to the control condition, where they see the stem after they have heard an unrelated word (e.g., subtil).

We used pairs of words consisting of a derived word and its stem or pairs of affixed words derived from the same stem (we investigate prefixed and suffixed words separately). We constructed five types of stimuli illustrated in Table 1. The first set (Condition 1) consisted of pairs of affixed words and their stem. The two words of 
TABLE 1

Sample of Stimuli Used

\begin{tabular}{lll}
\hline Condition & Morphological type & \multicolumn{1}{c}{ Example } \\
\hline Transparent & Prefixed/Stem & impartial/PARTIAL \\
Opaque & Prefixed/Stem & imberbe/BARBE \\
Derived & Prefixed/Prefixed & retourner/CONTOURNER \\
Phonological & PsPrefixed/PsStem & adorer/DORER \\
Transparent & Suffixed/Stem & brutal/BRUTE \\
Opaque & Suffixed/Stem & circulaire/CERCLE \\
Derived & Suffixed/Suffixed & respectueux/RESPECTABLE \\
Phonological & PsSuffixed/PsStem & louper/LOUP \\
Semantic & NA & personne/INDIVIDU \\
\hline
\end{tabular}

Note. Ps $=$ pseudo NA $=$ not applicable.

each pair were morphologically related, phonologically transparent [the stem had the same phonetic form, both on its own and when it was part of the derived word (e.g., frontal-front)], and semantically transparent. These contrasted with a further set of words (Condition 2) where the relationship between prime and target was phonologically and orthographically opaque, the prime being an allomorph of the target. An example is the case of chaleur-chaud, where the stem had a different phonetic and orthographic form in isolation from its form as part of a derived word. In the first condition, facilitating priming should be obtained if, as we assume, the recognition of the word involves the access of the stem morpheme and the associated affix. This is an account of priming based on shared morphemes at a central lexical representation level. What we need to exclude with Condition 2 is the possibility that any priming effect obtained in Condition 1 is simply due to the surface phonetic overlap between prime and target. To the extent that priming in this task is morphemic, the amount of priming should not be affected by these variations in the surface phonetic transparency of the relationship between derived word and stem. Two nonmorphological conditions were included: the first (Condition 3) contained word pairs that were not morphologically related, but which overlapped phonologically (from word onset). An example of such pair is louper-loup. The shorter of the two words (e.g., loup) was transparently contained in the longer word. If we find a priming effect in this case, we would be unable to argue that any priming we found for morphologically related pairs was due to their morphological relationship. It could be caused simply by the phonological relationship between them. Condition 4 consisted of word pairs which were semantically but not morphologically or phonologically related (e.g., placer-situer).

We added a fifth condition, where both words (prime and target) were derived words. Inside each pair words shared the same stem. Derived words sharing the same stem should prime each other for the same reason that derived words prime their stem. A pair like respectable-respectueux should be represented as sharing the stem, respect. When the subject hears the prime respectable, respect should be accessed. This same stem will be accessed when the subject subsequently sees the target respectueux, and residual activation of the stem should lead to faster lexical decision latencies. That is unless, as proposed by Marslen-Wilson and his collaborators, words sharing a morpheme and an initial cohort inhibit each other and that the cross-modal paradigm is sensitive to this process; in that case we should observe that two suffixed words do not prime each other while prefixed words do. 


\section{METHOD}

\section{Materials}

We selected 135 prime-target pairs that were divided into the five groups for the conditions outlined in Table 1. Sixty of the pairs, forming Condition 1 and 2, consisted of a derivationally affixed form and its associated free stem; half of the derivationally affixed forms were prefixed words and the other half were suffixed words. Thirty of the pairs, which formed Condition 5, consisted of derivationally affixed form pairs: 15 pairs of prefixed words sharing the same stem, and 15 pairs of suffixed words sharing the same stem. The pairs were matched across conditions for frequency, number of syllables, and grammatical category.

In Condition 1 (Transparent condition), the prime-target pairs were phonologically transparent in that the stem had the same phonetic form when it appeared in isolation and when it was part of the derived word (e.g., brutal-brute and incomplet-complet). Condition 2 (Opaque condition) consisted of derivedstem pairs that were phonologically opaque in that the stem had a different phonetic form in isolation compared with when it appeared in the derived word (e.g., surdité-sourd and imberbe-barbe). Condition 3 (Phonological condition) was made up of words that were not morphologically related but that overlapped phonetically (e.g., charité-char and insecte-secte). Condition 5 (Derived condition) was made of pairs of derived words (e.g., balayage-balayeur and rejoindre-disjoindre); we chose suffixed words that had the same surface frequency; this was impossible for prefixed words so we counterbalanced the role (prime or target) of the one that is more frequent (see Meunier \& Segui, 1999b). All our morphologically related pairs were semantically transparent (using the pretest of Marslen-Wilson et al., 1994) as judged by a panel of four judges. Condition 4 consisted of prime-target pairs (e.g., placer-situer), which were semantically related but not morphologically or phonologically related.

For each of the 135 prime words, we selected a control (or baseline) word that matched the prime in frequency, number of syllables, and form class. None of the control items were morphologically, semantically, or phonologically related to the targets. The priming effect is measured by comparing response time to the target word following the related prime with response time following the control word.

We constructed filler material (made of words and nonwords) to significantly dilute the proportion of related items encountered by the subject in the experiment and to equalize the word-nonword answer proportion. The purpose is to deter the participants from developing strategies based on expectation about the relationship between primes and targets. To this end we added filler pairs falling into three categories as follows: (1) Fifteen fillers consisted of word/nonword pairs in which there was a partial overlap between the prime and the nonword target (e.g., camion-camale*). Forty-five further fillers consisted of word-nonword pairs such as garnement-garne* in which the target was fully contained within the prime. These two sets of fillers ensured that not all prime-target pairs, which overlapped formally, had real words as targets. (2) Ninety-two fillers consisted of morphologically and phonologically unrelated word-word pairs (e.g., lapereau-hameçon). We included these items to increase the percentage of unrelated word pairs in the stimulus set. (3) To balance the number of word and nonword targets, 167 additional word/nonword pairs were constructed with no phonological relationship between prime and target (e.g., tableau-calobre).

This gave a total of 227 real-word-real-word pairs and 227 real-word-nonword pairs. Related pairs made up less than $30 \%$ of the stimuli encountered by the subjects. To avoid repetition within subjects, we split materials into two lists presented to separate groups of participants. A target appeared only once in each list: with its related prime in one version, and its unrelated control in the other. The number of pairs in each condition was fully counterbalanced across lists. We had two experimental lists of 454 items each so that each subject sees half of each category with a related prime and the other half with an unrelated prime. The visual list of target was the same for all subjects. The experiment started with 20 practice pairs which were followed by 10 warm-up pairs and the 454 test and filler pairs.

\section{Procedure}

All primes were recorded by a female native speaker of French onto DAT tape. They were then stored on a computer at a sampling rate of $22 \mathrm{kHz}$ and segmented independently. This allowed us to control the timing relationship between the prime and the visually presented target. One way to deter the subjects from developing strategies based on expectations about likely relations between primes and targets is to keep the stimulus onset asynchrony (SOA) between prime and target as short as possible. Immediately at the offset of the prime, which was presented binaurally to the subject, the target word was displayed on a CRT screen in front of the subject until he/she answered. The subject's task was to press one response key if the target was a real word and another if it was a nonword, with the instruction to respond as quickly and accurately as possible. Subjects were tested individually in a quiet room. There were 
four breaks in the test session; one after the practice and three through the main test sequence. The entire session lasted about $30 \mathrm{~min}$.

The exact sequence of stimulus events within each trial was as follows. A fixation point was displayed on the CRT screen in front of the subject for $500 \mathrm{~ms}$. This was followed by the auditory prime word. At the acoustic offset of this word, the visual probe was presented for $500 \mathrm{~ms}$. After the subject answered there was a pause of $500 \mathrm{~ms}$ and then a new trial was initiated (marked by the reappearance of the fixation point).

\section{Participants}

We tested 38 native speakers of French. They were students in psychology in their second year and between the ages of 18 and 30 years.

\section{RESULTS}

We analyzed the results for prefixed words and suffixed words totally separately because of the differences already observed between these two types of words (Meunier, 1997). Analyses of variance (ANOVA) were conducted on the reaction time data. An $\alpha$ level of .05 was used for all statistical tests. We conducted analyses across both participants $(F 1)$ and items $(F 2)$. Response latencies of more than $1500 \mathrm{~ms}$ (measured from the appearance of the target word on the screen) were removed from the data set. A total of 10 observations $(0.2 \%)$ were removed by this procedure. The means of reaction times and response error rates for the data are given in Table 2.

Overall for prefixed word conditions (Transparent, Opaque, and Derived conditions) we observed a facilitatory priming effect $[F 1(1,37)=4.61, p<.04 ; F 2(1$, $42)=24.73, p<.0001]$ : the identification of a target word was faster if the prime was a prefixed word belonging to the same morphological family as the target. This effect did not interact with the type of morphological relationship shared by the prime and the target $[F 1(2,74)=2.28, n s ; F 2(2,42)=1.04, n s]$. Planned comparisons confirmed this pattern: We observed a priming effect between a prefixed word and its stem, both in the subject $[F 1(1,36)=4.01, p<.05]$ and item analyses $[F 2(1$, $14)=3.17, p<.01]$. We still observed a significant priming effect when the acoustic realization of the stem differed when it was realized as a free lexical item and when it was realized as part of a prefixed word $[F 1(1,36)=4.28, p<.05 ; F 2(1,14)=$ $2.29, p<.04]$. We found a facilitatory priming effect between two prefixed words derived from the same stem $[F 1(1,36)=6.51, p<.02 ; F 2(1,14)=3.15, p<.01]$.

TABLE 2

Mean Lexical Decision Times and Error Rates

\begin{tabular}{|c|c|c|c|c|c|c|}
\hline \multirow[b]{2}{*}{ Condition } & \multirow[b]{2}{*}{ Morphological type } & \multicolumn{2}{|c|}{ Test } & \multicolumn{2}{|c|}{ Control } & \multirow[b]{2}{*}{ Difference } \\
\hline & & $M$ & $\begin{array}{l}\text { Error } \\
\text { rate }\end{array}$ & $M$ & $\begin{array}{l}\text { Error } \\
\text { rate }\end{array}$ & \\
\hline Transparent & Prefixed/Stem & 538 & 0.7 & 568 & 2.8 & $30 *$ \\
\hline Opaque & Prefixed/Stem & 514 & 0.4 & 532 & 3.2 & $18 *$ \\
\hline Derived & Prefixed/Prefixed & 608 & 4.6 & 643 & 0.1 & $35^{*}$ \\
\hline Phonological & PsPrefixed/PsStem & 592 & 9.5 & 598 & 14.7 & 6 \\
\hline Transparent & Suffixed/Stem & 514 & 0.7 & 557 & 4.9 & $43^{*}$ \\
\hline Opaque & Suffixed/Stem & 517 & 1.1 & 521 & 0.4 & 4 \\
\hline Derived & Suffixed/Suffixed & 591 & 3.5 & 624 & 7.7 & $33^{*}$ \\
\hline Phonological & PsSuffixed/PsStem & 588 & 8.1 & 591 & 9.8 & 3 \\
\hline Semantic & NA & 583 & 5.3 & 606 & 6.3 & $23 *$ \\
\hline
\end{tabular}

Note. $\mathrm{NA}=$ not applicable; $\mathrm{Ps}=$ pseudo.

$* p<.05$. 
We observed no significant formal priming effect between two words phonologically related (the same type of overlap as for a prefixed word and its stem) but morphologically unrelated $(F 1<1 ; F 2<1)$.

Globally for the suffixed word conditions (Stem, Opaque, and Derived conditions) we also observed a facilitatory priming effect $[F 1(1,37)=10.31, p<.003 ; F 2(1$, $42)=22.74, p<.0001]$; however, this effect interacted with the type of morphological relationship shared by the prime and the target $[F 1(2,74)=4.42, p<.02 ; F 2(2$, $42)=4.23, p<.03]$. More precisely, the Transparent condition interacted with the Opaque condition $[F 1(1,37)=7.29, p<.01 ; F 2(1,28)=7.34, p<.02]$, but it did not interact with the Derived condition $[F 1<1 ; F 2<1]$. Planned comparisons confirmed this pattern: Suffixed words facilitated the identification of their stems $[F 1(1,36)=23.14, p<.001 ; F 2(1,14)=3.89, p<.002]$ but only when the stem was identical phonologically on its own and within a suffixed word. In the case of a phonologically opaque relationship between a suffixed word and its stem no priming effect was observed $(F 1<1 ; F 2<1)$. A suffixed word primed another suffixed word derived from the same stem $[F 1(1,36)=4.27, p<.05 ; F 2(1,14)=3.65$, $p<.003$ ]. No formal priming was observed between two words morphologically not related but that shared the same phonological relationship as a suffixed word and its stem $(F 1<1 ; F 2<1)$. Finally and as expected using the cross-modal priming paradigm, the semantic priming effect was significant $[F 1(1,36)=4.86, p<.05$; $F 2(1,14)=2.84, p<.02]$.

\section{DISCUSSION}

In this experiment, we have approached the problem of the processing of morphologically complex words and their lexical representation in French by using a procedure of cross-modal priming (auditory-visual). We can summarize our results as follows.

1. The presentation of prefixed words facilitated the subsequent identification of their stem. This morphological priming effect occurs even when the phonological relationship between the two words is opaque, such between imberbe-barbe. For suffixed words the pattern of results differed: We observed a significant facilitatory priming effect only when the morphological relationship between suffixed words and their stem is phonologically transparent.

2. For the two types of derived words we observed a facilitatory priming effect between words derived from the same stem (pairs of prefixed word and pairs of suffixed words). These effects confirm the existence of facilitatory links between words belonging to the same morphological family, links that could occur through the stem.

3. No pure phonological priming effect was observed for either pseudoprefixed words or pseudosuffixed words. That implies that the morphological priming effects observed are not only due to formal overlap between primes and targets; indeed for phonological pairs such as alarme-larme and louper-loup no facilitatory effect emerged.

4. We observed the classic facilitatory semantic priming effect for pairs of semantically related words such as hauteur-altitude. However, we argue that such an effect does not really question the nature of our morphological priming (see on this point Bentin \& Feldman, 1990; Henderson, Wallis, \& Knight, 1984). The first point to underline is that even if the degree of semantic relatedness within morphological pairs and within semantic pairs is comparable, the nature of the semantic relationship is completely different. In one case the words are almost "synonymous" and in the 
other the words share a part of their meanings. This complicates the extrapolation of the results observed for the semantic condition to the interpretation of the results observed for the morphological conditions. In any case, if our morphological effect was in fact due to the semantic relationship between words belonging to the same morphological family then we should have observed a facilitatory priming effect between a suffixed word and its stem even if their phonological relationship is opaque because their semantic relationship is transparent. Such an effect was not observed; moreover, the size of the semantic effect $(23 \mathrm{~ms})$ is less than the mean morphological effect $(32 \mathrm{~ms})$. It still could be that the morphological effects observed in our experiment are due not only to morphological relatedness between the prime and the target but also to semantic relatedness between the two words. Our argument is that our results observed in the morphological conditions cannot be explained only by the semantic link between two words belonging to the same morphological family.

This experiment is the first to use a cross-modal priming paradigm in French. The results are clear-cut and show that morphological priming effects are not only due to formal overlap between primes and targets. The pattern observed suggests that morphologically complex words are decomposed into their morphemic constituents during their identification: prefixed words prime their stem and also another prefixed word derived from the same stem; suffixed words prime their stem as well as another suffixed word sharing the same stem. However while allomorphic prefixed words prime their stems, allomorphic suffixed words do not.

Suffixed and prefixed words may not be considered as homogeneous in a number of respects, and one of the major differences is in the sequential order of stem and affix. In suffixed words, the stem precedes the affix, whereas in prefixed words the affix precedes the stem. It has been suggested by many authors that this difference in the sequential organization of the morphemic components within suffixed and prefixed words affects identification processes (Beauvillain, 1996; Feldman \& Larabee, 2001). Studies done in French and contrasting the two types of derived words show differences in processing. For example, while evidence of morphological decomposition for prefixed words is observed, the effect of cumulative frequency (i.e., frequency of the morphological family) is only present for suffixed words, suggesting that the decomposition of prefixed words does not occur preliminary to lexical access (Beauvillain, 1996; Meunier, 1999). In fact no evidence of decomposition prior to lexical access has ever been observed in French for prefixed words. The overall picture of the results published in French on derivational morphology leads to the following: There is a morphemic decomposition for the two types of affixed words. However, this decomposition operates at different stages of the identification process depending on the sequential organization of morphemic constituents within a word. When a subject encounters a suffixed word, the stem is integrated first; which means that the decomposition process can take place without disturbing left-to-right processing. For prefixed words, prefixes would need to be stripped off in order to access the stem first; many experiments have shown that this is not the case (see Meunier, 1999). In fact for prefixed words decomposition occurs after access and not as part of the access process itself. But why perform decomposition if it is not prelexical? The "postlexical access" decomposition of prefixed words could be due to the fact that in French prefixed words are very transparent morphologically and semantically. Most French prefixes have their own meaning such as re- meaning "again" or inmeaning "not." So when we derive a stem by adding a prefix, we add an aspect of meaning to the word without changing its syntactic properties. Moreover, prefixes mostly correspond to a syllable (in-, $a-$, dé-, $\left.r e^{-}\right)$so by adding a prefix to a stem no resyllabification process is needed, and the morphological structure matches a syllabic boundary (Duchet, 1997). Suffixation is totally different: Most French suffixes 
do not mean anything by themselves such as -able in respectable; the function of a suffix is mostly to change the syntactic category of the stem. Also, very often, the suffixation process implies a resyllabification of the stem. These linguistic differences interact with the sequential organization of each type of word for the subject: for suffixed words, the stem is heard first, giving the listener immediate access to semantic information associated with it; for prefixed words, not only is access to the stem delayed, but also the initial segments of the word are relatively less informative. These linguistic and sequential differences between prefixed words and suffixed words could explain why, for suffixed words, decomposition occurs in an early stage of the identification process, while it happens later for prefixed words. We argue that it is because decomposition occurs at a very early stage for suffixed words that we observe no priming between an allomorphic suffixed form and its stem. First, this lack of priming can seem puzzling given that we should at least observe a semantic priming effect between a semantically transparent suffixed word and its stem, even if their phonological relationship is opaque. We propose that the lack of priming observed between an allomorphic suffixed word and its stem reflects inhibition processes within the lexicon. If, as postulated by Marslen-Wilson et al. (1994), an allomorph activates a phonologically abstract shared lexical representation, then the selection of the adequate phonological form will imply the inhibition of the other forms that could be taken by the lexical representation. Allomorphic forms like surdité and sourd are mutually exclusive for the abstract lexical representation /sourd/. The choice of one phonological form will exclude and inhibit the other possible realization of the lexical representation. For prefixed words, as the decomposition process does not occur at the same stage and does not in consequence fulfill the same needs, no such inhibitory process takes place and priming effect is observed between allomorphic forms. To summarize, our results can be explained by a model where both types of morphological words are decomposed but at different stages of their identification. In the lexicon, the phonologically abstract representations of stems are activated when derived words are encountered. In the case where the lexical representation is initiated at an early stage of the identification process, inhibitory processes will occur between the different phonological forms of a given lexical representation. However, there is another way to interpret the lack of priming between an allomorphic suffixed word and its stem. For allomorphic suffixed words, the phonological change is on the first part of the word, and given the importance of word first sequence in auditory processing, this could compromise the activation of the stem, reducing it or delaying it. Indeed, if we look at the allomorphic prefixed word condition, we can see that the size of the priming effect is reduced (even if the difference is not statistically significant) compared to the transparent condition $(18 \mathrm{~ms}$ vs $30 \mathrm{~ms})$. This could suggest that the same phenomenon is happening for the two types of derived words and that there is an effect of phonological mismatch between derived words and stem. The earlier the phonological change is encountered in the allomorphic prime word the more likely it is to compromise the activation of the stem. Further experiments should be performed to explore this point more precisely.

Our results obtained in French are broadly comparable to those observed in English by Marslen-Wilson et al. (1994). For prefixed words the patterns observed in French and in English are very similar; however, two differences emerge between the English and the French results for suffixed words: We observe no priming between an allomorphic suffixed word and its stem while Marslen-Wilson et al. (1994) report a significant priming effect in this case. Also we do observe a facilitatory priming effect between two suffixed words derived from the same stem (replicated with other items in Meunier \& Marslen-Wilson, 2000) while Marslen-Wilson et al. (1994) did not (replicated by Feldman \& Larabee, 2001). The French and the English experiments were closely matched in their design and the characteristics of the linguistic material. 
Taken in isolation, English and French derivation processes are very similar in the way they are applied. But the overall picture of properties of the two languages is very different. We argue that it is the specific properties of the language itself, such as the rhythms, which can explain the different pattern of results observed. English is a stress language with a strong-weak pattern. The stress is on the first part of the word; the stem is acoustically very salient while, at the end of the word, the suffix is not. It is the reverse in French: French is a syllabic language with short-long patterns. The stem is short while the suffix is long. In French, the stress located on the suffix could speed up the selection process of the suffixed word among the other suffixed words of its morphological family. The consequence would be a short-lived inhibition of the other suffixed candidates; inhibition that would be gone by the end of the prime word identification. In English, given the lack of accent on the suffix, the selection process of the suffixed word among the other candidates would be slower; that could imply a long-lived inhibition that interacts with the identification of the target. An easy way of testing this would be to add delay between primes and targets. According to our interpretation, in English it should result in a facilitatory priming effect between two suffixed words derived from the same stem. The same type of explanation explain the difference in the priming effect observed between allomorphs and their stems in French and in English. Following the same logic as previously, in French, the stem is not stressed so the inhibition between the different phonological forms of the stem representation (as explained earlier) will be longlived and will interfere with the target identification process. In English, the stem being stressed, the inhibition will be short-lived and gone by the time the target starts to be processed. Further experiments should be done to confirm this interpretation.

The results of our experiment confirm that the morphological system cannot be considered independently and make clear that cross-linguistic comparisons may only be informative if the general characteristics of the languages are also taken into account.

\title{
APPENDIX A
}

\section{Translation of French Words and Word Pairs Used as Examples in the Text}

\author{
refaire-faire: redo-do \\ chaleur-chaud: heat-hot \\ imberbe-barbe: without beard-beard \\ jardinier-jardinage: gardener-gardening \\ refaire-défaire: redo-undo \\ alarme-larme: alarm-tear \\ acidité-acide: acidity-acid \\ charité-char: charity-chariot \\ infirmière-docteur: nurse-doctor \\ bestial-bête: bestial-beast \\ subtil: subtle \\ frontal-front: frontal-forehead \\ louper-loup: to miss-wolf \\ placer-situer: to put-to situate \\ respectable-respectueux: respectable-respectful \\ surdité-sourd: deafness-deaf \\ insecte-secte : insect-sect \\ balayage-balayeur: sweeping-road sweeper \\ rejoindre-disjoindre: to rejoin-to separate \\ camion: truck \\ garnement: rascal \\ lapereau-hameçon: baby rabbit-hook \\ hauteur-altitude: height-altitude
}




\section{APPENDIX B}

\section{Experiment Materials_-Prefixed and Pseudoprefixed Conditions}

\section{Transparent condition (prefixed/stem)}

impartial/PARTIAL; emboîter/BOITE; engelure/GELER; abaisser/BAISSER; enfermer/FERMER; débloquer/BLOQUER; dégraisser/GRAISSE; incomplet/COMPLET; infidèle/FIDELE; enchaîner/CHAINE; affaiblir/FAIBLE; découper/COUPER; réactif/ACTIF; dégivrer/GIVRER; incapable/CAPABLE

Opaque condition (prefixed/stem)

imberbe/BARBE; embraser/BRAISE; encoignure/COIN; accoster/COTE; encolure/COU; décoloré/ COULEUR; déculpabilisé/COUPABLE; incrédule/CROIRE; indestructible/DETRUIRE; endolorie/DOULEUR; affamer/FAIM; déflorer/FLEUR; réfrigérer/FROID; déguster/GOUT; invincible/VAINCRE

Derived condition (prefixed/prefixed) dépeupler/SURPEUPLE; reboucher/DEBOUCHER; surimpression/REIMPRESSION; accrocher/DECROCHER; desserrer/ENSERRER; déplumer/REMPLUMER; méconnaître/RECONNAITRE; soulever/ENLEVER; immobiliser/DEMOBILISER; apposer/DEPOSER; rejoindre/DISJOINDRE; dépeindre/REPEINDRE; annoter/CONNOTER; contourner/RETOURNER; enraciner/DERACINER.

Phonological condition (pseudoprefixed word/pseudostem) insecte/SECTE; enrouer/ROUE; enfantin/FAON; adorer/DORER; empêcher/PECHER; déprimer/PRIME; décaper/CAPE; interner/TERNE; impact/PACTE; entendre/TENDRE; alarme/LARME; décor/COR; redingote/DINGUE; défendre/FENDRE; relent/LENT

\section{APPENDIX C}

\section{Experiment Materials-Suffixed and Pseudosuffixed Conditions}

\section{Transparent condition (suffixed/stem)}

saluer/SALUT; brutal/BRUTE; frontal/FRONT; acidité/ACIDE; cellulaire/CELLULE; créditeur/CREDIT; fournil/FOUR; férocité/FEROCE; verbal/VERBE; toiture/TOIT; finition/FINIR; mortel/MORT; jugement/JUGE; regretter/REGRET; pliage/PLIER

Opaque condition (suffixed/stem) aérer/AIR; bestial/BETE; buccal/BOUCHE; brièveté/BREF; circulaire/CERCLE; chaleur/CHAUD; chenil/CHIEN; clarté/CLAIR; digital/DOIGT; lecture/LIRE; location/LOUER; tactile/TOUCHER; surdité/SOURD; materner/MERE; breuvage/BOIRE

Derived condition (suffixed/suffixed) gâterie/GATEUX; enviable/ENVIEUX; extrémisme/EXTREMITE; glaciaire/GLAÇON; intégrité/INTEGRISME; production/PRODUCTIVITE; respectueuX/RESPECTABLE; satanique/SATANISER; balayage/BALAYEUR; pensionnat/PENSIONNAIRE; bavure/BAVOIR; brûleur/BRULURE; digestion/DIGESTIF; facilitation/FACILITATEUR; ossature/OSSEMENTS

Phonological condition (pseudosuffixed word/pseudostem) louper/LOUP; mental/MENTHE; bancal/BANQUE; charité/CHAR; solaire/sOL; traiteur/TRAIT; persil/PERCER; banal/BAS; rature/RAT; compassion/COMPAS; fossile/FOSSE; limité/LIME; chômage/CHAUME; douteux/DOUX; comique/COMMIS

\section{APPENDIX D}

\section{Experiment Materials-Semantic Condition}

modification/CHANGEMENT; constater/OBSERVER; coûteuX/DISPENDIEUX; commander/DIRIGER; hauteur/ALTITUDE; chant/MELODIE; copieuX/ABONDANT; penser/MEDITER; habituer/ACCOUTUMER; individu/PERSONNE; sommeiller/DORMIR; situer/PLACER; gros/CORPULENT; espionner/SURVEILLER; dorloter/CHOYER.

\section{REFERENCES}

Beauvillain, C. (1996). The integration of morphological and whole-word form information during eye fixations on prefixed and suffixed words. Journal of Memory and Language, 35, 801-820. 
Bentin, S., \& Feldman, L. B. (1990). The contribution of morphological and semantic relatedness to repetition priming at short and long lags: Evidence from Hebrew. Quarterly Journal of Experimental Psychology, 42A, 693-711.

Burani, C., \& Laudanna, A. (1992). Units of representation for derived words in the lexicon. In R. Frost \& L. Katz (Eds.), Orthography, phonology, morphology and meaning. Amsterdam: NorthHolland.

Butterworth, B. (1983). Lexical representation. In B. Butterworth (Ed.), Language production (pp. 257294). London: Academic Press.

Bybee, J. L. (1985). Morphology: A study of the relation between form and meaning. Amsterdam: J Benjamins.

Caramazza, A., Miceli, G., Silveri, M. C., \& Laudanna, A. (1985). Some aspects of language processing revealed through the analysis of acquired aphasia: The lexical system. Annual Rewiew of Neurosciences, 11, 395-421.

Comrie, B. (1981). Language universals and linguistic typology, Oxford, UK: Basil Blackwell.

Drews, E., \& Zwitserlood, P. (1995). Effects of morphological and orthographic similarity in visual word recognition. Journal of Experimental Psychology: Human Perception and Performance, 21, 1098-1116.

Duchet, J.-L. (1997). Les préfixés. Nantes, France: Ecole d'été sur la morphologie.

Feldman, L. B. (1994). Beyond orthography and phonology: Differences between inflections and derivations. Journal of Memory and Language, 33, 442-470.

Feldman, L. B., \& Larabee, J. (2001). Morphological facilitation following prefixed but not suffixed primes: Lexical architecture or modality-specific processes? Journal of Experimental Psychology: Human Perception and Performance, 27, 680-691.

Fowler, C. A., Napps, S. E., \& Feldman, L. B. (1985). Relations among regularly and irregularly morphologically related words in the lexicon as revealed by repetition priming. Memory \& Cognition, 13, $241-255$.

Frauenfelder, U., \& Schreuder, R. (1992). Constraining psycholinguistic models of morphological processing and representation: The role of productivity. In G. Booij \& J. van Marle (Eds.), Yearbook of morphology 1991. Amsterdam: Kluwer.

Frost, R., Katz, L., \& Bentin, S. (1987). Strategies for visual word recognition and orthographical depth: A multilingual comparison. Journal of Experimental Psychology: Human Perception and Performance, 13, 104-115.

Grainger, J., Colé, P., \& Segui, J. (1991). Masked phonological priming in visual word recognition. Journal of Memory and Language, 30, 370-384.

Henderson, L., Wallis, J., \& Knight, K. (1984). Morphemic structure in lexical access. In H. Bouma \& D. Bouwhuis (Eds.), Attention and performance X: Control of language processes. Hillsdale, NJ: Erlbaum.

Katz, L., \& Feldman, L. B. (1983). The relation between pronunciation and printed words in deep and shallow orthographies. Journal of Experimental Psychology: Learning, Memory, and Cognition, 9, $157-166$.

Kempley, M., \& Morton, J. (1982). The effects of priming with regularly and irregularly related words in auditory word recognition. British Journal of Psychology, 73, 441-454.

Manelis, L., \& Tharp, D. (1977). The processing of affixed words. Memory \& Cognition, 5, 690-695.

Marslen-Wilson, W. D., Tyler, L. K., Waksler, R. \& Older, L. (1994). Morphology and meaning in the English mental lexicon. Psychological Review, 101, 3-33.

Marslen-Wilson, W. D., \& Welsh, A. (1978). Processing interactions and lexical access during wordrecognition in continuous speech. Cognitive Psychology, 10, 29-63.

Marslen-Wilson, W., \& Zhou, X. (1999). Abstractness, allomorphy, and lexical architecture. Language and Cognitive Processes, 14, 321-352.

McQueen, J., \& Cutler, A. (1998). Morphology in word recognition. In A. Spencer \& A. Zwiky (Eds.), The handbook of morphology (pp. 406-428). Oxford, UK: Blackwell.

Meunier, F. (1999). Morphologie et traitement du langage parlé. Presses Universitaires du Septentrion, France (published PhD).

Meunier, F., \& Marslen-Wilson, W. (2000). Suffixed word lexical representations in French. Presented at Spoken word access processes (SWAP), May 29-31, Nijmegen, The Netherland.

Meunier, F., \& Segui, J. (1999a). Frequency effect in auditory word recognition: The case of suffixed words. Journal of Memory and Language, 41, 327-344. 
Meunier, F., \& Segui, J. (1999b). Morphological priming effect: The role of surface frequency. Brain and Language, 68, 54-60.

Rey, A (Ed.). (1995). Dictionnaire historique de la langue française. Dictionaries Le Robert.

Schreuder, R., \& Baayen, R. H. (1995). Modelling morphological processing. In L. B. Feldman (Eds.), Morphological aspects of language processing (pp. 131-156). Hillsdale, NJ: Erlbaum.

Stanners, R. F., Neiser, J. J., Hernon, W. P., \& Hall, R. (1979). Memory representation for morphologically related words. Journal of Verbal Learning and Verbal Behavior, 18, 399-412.

Taft, M., \& Forster, K. I. (1975). Lexical storage and retrieval of prefixed words. Journal of Verbal Learning and Verbal Behavior, 14, 638-647. 